\title{
Locomotor activity and exploration: The use of traditional manipulators to dissociate these two behaviors in the rat
}

\author{
MARK LEYLAND \\ Chemical Defence Establishment, Porton Down, Salisbury, Wilts SP4 0JQ, England \\ and \\ TREVOR ROBBINS and SUSAN D. IVERSEN \\ University of Cambridge, Cambridge, England
}

\begin{abstract}
An apparatus designed by Berlyne was used to dissociate locomotor activity and inspective exploratory responses with the aid of traditional manipulators. In this apparatus, novel and complex stimulation increased exploration but did not affect locomotor activity (LA). d-amphetamine $(1.5 \mathrm{mg} / \mathrm{kg})$ increased LA but decreased exploration. These findings provide a double dissociation of the behavioral components. In addition, low intrasubject correlations for the two behaviors were demonstrated. Results are discussed with reference to the need for simultaneous separate measures to obtain valid indices of exploratory behavior and LA.
\end{abstract}

When placed in a novel environment, rats move around. At first sight, this behavior seems no more than simple ambulation. However, if the novelty or the degree of complexity of stimulation in the environment is manipulated, the amount and nature of the motor behavior varies (Berlyne, 1950; Schneider \& Gross, 1965; Woods \& Davidson, 1964). Such results indicate that general activity in any particular situation is compounded of what one might describe as "pure locomotor" behavior (Lore, 1968) together with an exploratory element, which may be manipulated by traditional elicitors, such as novelty and complexity of environmental stimulation.

It has often been suggested that in studies of spontaneous locomotor behavior, these two contributing components have neither been recognized nor independently measured (Berlyne, 1960; Bindra \& Spinner, 1958; Lester, 1968). This has been felt to be particularly true of experiments using apparatus such as the Y-maze, where a measure of locomotion is often assumed to be exploratory in nature with no prior rationale for such an assumption (e.g., Montgomery, 1955; Steinberg, Rushton, \& Tinson, 1961). Simultaneous observation of both behavioral components has been attempted in the past by Corman and Shafer (1968), Foshee, Vierck, Meier, and Federspiel (1965), and Kumar (1969). However, in none of these studies was there an attempt to manipulate each of the two behavioral components separately, by means of independent variables within the same experimental design, nor was a low intrasubject correlation between the two behavioral components demonstrated.

Robbins and Iversen (1973), using a modified version of Berlyne's box (Berlyne, 1955), have demonstrated that amphetamine will simultaneously increase locomotor activity (LA) and decrease time spent investigating or inspecting novel objects. This result appears to dissociate the two behavioral components, but this interpretation is complicated by high correlations between LA and inspective exploration reported in the same paper. A closer examination of intrasession data in that experiment reveals that (a) most exploration occurred during the first $2 \mathrm{~min}$, and (b) correlations between the behaviors over this period were near to zero. These observations indicated that it is not necessarily the case that the two measures are both indices of the same behavior as the high correlations alone would suggest. Indeed, at any time when both behaviors are occurring to an appreciable extent the correlations were near zero.

It was considered that the most appropriate method for demonstrating the separate nature of the two behavioral types involved was to perform a double dissociation by the use of a pair of traditional manipulators of the behaviors, and the present experiments report such a dissociation.

Novel and complex stimuli were chosen to manipulate exploration as in previous studies (Berlyne, 1955; Woods \& Davidson, 1964). The universal finding has been that novelty enhances exploration and that this enhancement is augmented by complexity. Familiar, complex stimuli, however, were reported not to be effective elicitors of exploration (Schneider \& Gross, 1965) when speed of approach was used as an index. In Experiment I, we have attempted to observe the effects on LA and inspective exploration 
GROUND PLAN

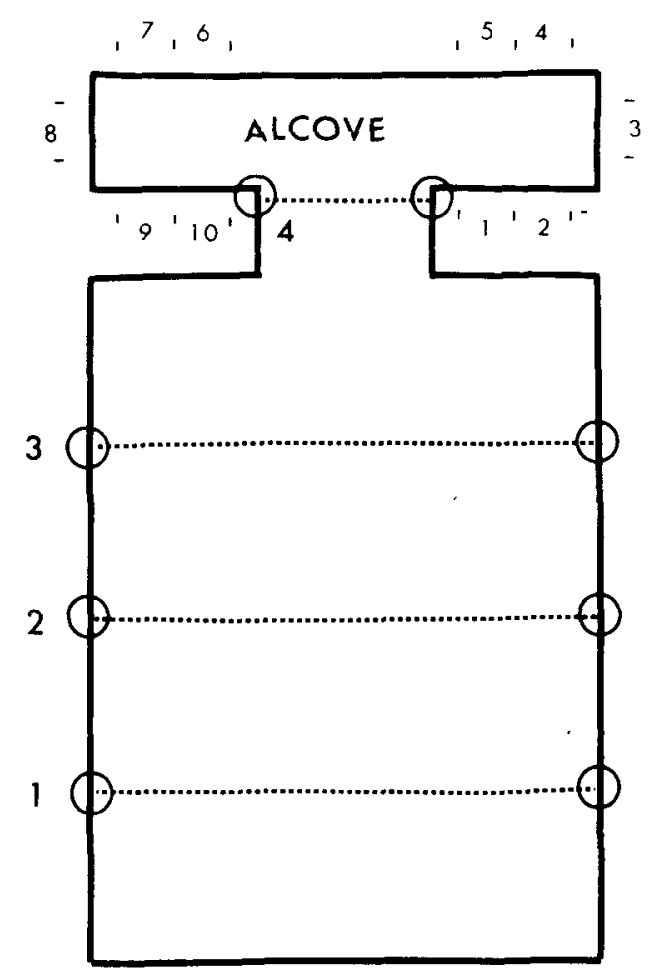

Photocell Beam

Photocell

Figure 1. Ground plan of the Berlyne box. Numbers around the alcove refer to placement of stimulus cards.

of novel and complex stimuli placed in the alcove section of the apparatus.

Because it is well known to increase LA in photocell boxes resembling the main chamber of the present apparatus, d-amphetamine was chosen to manipulate locomotor activity. By contrast, it has been found that inspective exploration is either unaffected or depressed by the drug (Kumar, 1969; Wimer \& Fuller, 1965). Effects of this drug on LA and inspective exploration were examined in Experiment II, which is discussed more fully below.

By using a similar apparatus and technique to Robbins and Iversen's (1973), it is possible to answer more questions relevant to their experimental situaiions: first, to determine the effects of novelty upon the behavior of rats in the Berlyne box, and second, to observe the effects of amphetamine on low, stable rates of exploration of previously habituated complex exploranda.

\section{EXPERIMENT I}

A modified version of Berlyne's box, similar to the apparatus of Robbins and Iversen (1973), was used, exploration being measured in terms of inspective responses to predefined stimulus objects presented in an alcove at one end of the box and LA being measured by photocells in the main chamber. This experiment assesses the effect of novelty and complexity in the design of visual stimulus cards on exploration and activity. We may predict, on the basis of previous results, that the novel stimuli will produce increased exploration and that this effect will be enhanced in a group exposed to more complex novel stimuli. Further, we may predict that exploration will decrease over trials in all groups but will decrease more slowly in a group given a new stimulus each day than in a group given the same stimuli each day. Effects of novel and complex stimulation on LA have not previously been examined.

\section{Methods}

Subjects. The experimental animals were 18 male albino rats of the Wistar strain, weighing $225 \pm 10 \mathrm{~g}$ at the time of testing. They were housed in groups of 4 , with ad-lib supply of standard laboratory chow and water.

Apparatus. The test apparatus (Figure 1) used in this study was derived from an apparatus designed by Berlyne (1955) to assess inspective behavior displayed to novel objects. It consisted of two compartments: a main chamber, $61.0 \times 45.6 \times 30.4 \mathrm{~cm}$ deep, where locomotor activity was recorded by Counters 1,2 , and 3 , and an alcove, $45.6 \times 6.7 \times 30.4 \mathrm{~cm}$. The two were joined by an alley measuring $10.1 \times 5.1 \times 30.5 \mathrm{~cm}$.

The stimuli used were the black and white visual patterns shown in Figure 2. Each was drawn on a card measuring $5.1 \times 30.4 \mathrm{~cm}$. Two cards of each design were presented simultaneously in the alcove, in the 10 positions marked in Figure 1, with one of each pair in each arm. The cards were reversible, being plain white on one side and patterned on the other. They were attached to the walls of the alcove by means of a bulldog clip at the top and by an adhesive "plasti-tak" at the bottom.

Procedure. Testing was carried out in the afternoon, in a room illuminated by a $100-\mathrm{W}$ overhead light. The rats were run in an irregular sequence and were transferred from the home cage to the apparatus by hand, and then placed in the center of the box with head pointing away from the alcove.

Before testing, each rat was habituated to the box for three consecutıve daily 10 -mın periods. The stimulus cards in the alcove were all reversed during this phase of the experiment so that the patterns could not be seen.

The animals were then divided arbitrarily into three groups of six each. Five daily 1 -min test sessions were given in which
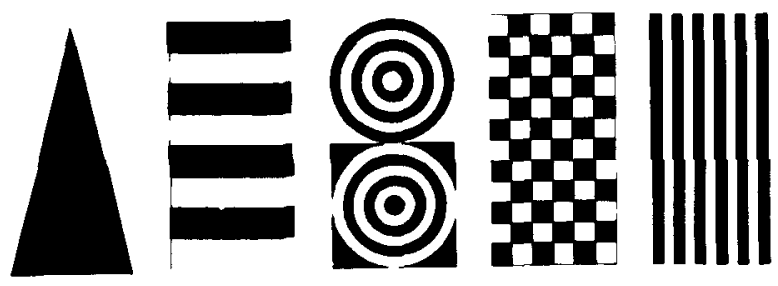

Figure 2. The five patterns used for the 10 stimulus cards. 


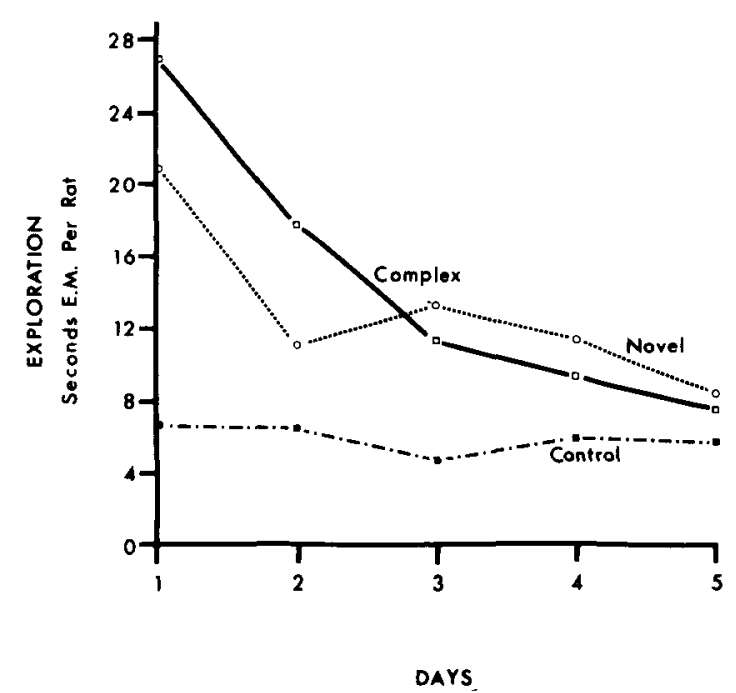

Figure 3. Experiment I: Mean duration of exploration (E.M.) in seconds for each of the three groups over the 5 successive test days.

groups experienced the following stimulus conditions: Group Icomplex-For this group, all 10 stimulus patterns were displayed in the same position on each trial. Group 2-novel-A different pair of identical, randomly positioned, stimulus patterns was displayed on each day, the eight remaining cards being blank. Group 3-control-All cards remained blank on all trials.

The following measures were taken: (a) locomotor activity assessed by the cumulative counts on the photocells, and (b) exploration (EM) assessed by recording the cumulative duration of inspective responses made to the stimuli during the 1 -min test. The inspective response criterion was (a) frontal (head or paw) contact with stimuli or (b) animal's head $<4 \mathrm{~cm}$ from stimulus with long axis of head $<60^{\circ}$ to stimulus card face.

\section{Results}

Mean levels of exploration of the stimulus cards by the three groups on each day are given in Figure 3. A two-way analysis of variance for repeated measures (Winer, 1962) revealed significant differences between groups $[F(2,15)=12.2, p<.01]$ and over days $[F(4,60)=10.9, p<.01]$. In addition, there was a significant Days by Groups interaction $[F(8,60)=3.26, p<.01]$. This interaction was examined by means of comparison testing using Student's $t$ over the first 2 days and the last 2 days of the experiment. Each experimental group ( 1 and 2$)$ was compared with the control group (3). Over the first 2 days of the experiment, both Group 1 (complex) and Group 2 (novel) explored significantly more than Group 3 (control) (t $>2.9, \mathrm{p}<.01$ ). These results do not imply anything about the relationship between Groups 1 and 2, so these groups were in turn compared and Group 1 found to explore more than Group $2(t=2.59, p<.025)$. Over the last 2 days of the experiment, there was no difference between the score of Complex Group 1 and Control Group 3. Novel Group 2, however, explored more during this period than the control $(\mathrm{t}=1.83, \mathrm{p}<.05)$ over this period. Hence, the interaction may be largely attributed to the decline in exploration in Complex Group 1 over the course of testing as compared with the other two groups.

Mean levels of LA for each group on each day are given in Figure 4. Analysis of variance revealed no significant differences in activity between groups or over days.

Intrasubject product-moment correlations of LA and EM on each day were carried out. The correlation coefficient was found to be less than 0.20 on each day except Day 2, when $r=0.39$, never approaching significance.

\section{Discussion}

In this study, a clear dissociation of exploration and locomotor activity was obtained. While novelty and complexity did not affect the level of LA, each greatly affected exploration in the predicted direction. Animals of Novel Group 2 explored more than the habituated control group, 3 , and this enhancement of exploration persisted so long as a new stimulus was provided on each day. Animals of Complex Group 1 explored more than Control Group 3 on the early trials, and the effect of novelty was here enhanced by the complexity of the stimuli so that these rats explored even more than the subjects of Group 2. However, since the same set of stimuli was presented to Group 1 rats in each of the five sessions, its novelty was reduced and by the ind of testing these rats explored no more than the habituated control group, 3. These findings are in complete agreement with previous results mentioned earlier.

Thus we have demonstrated, first, that effective manipulators of exploration have no effect on loco-

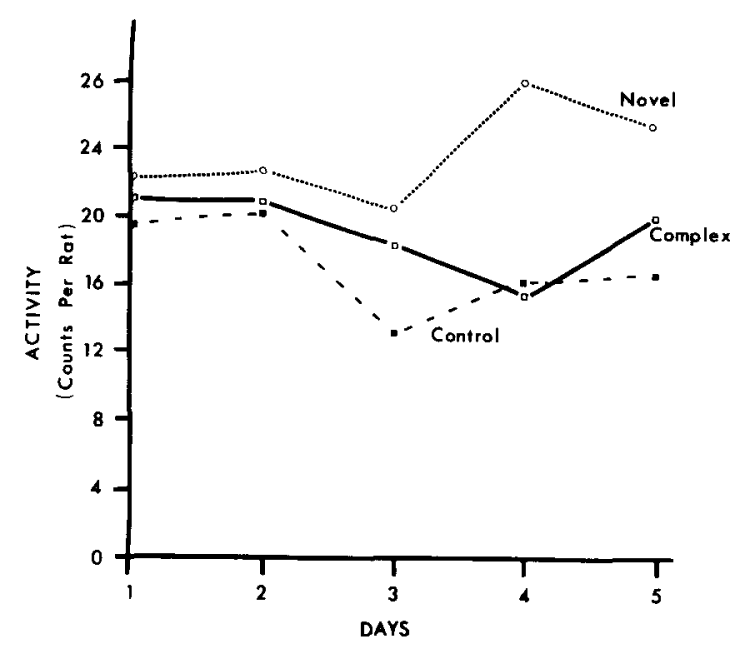

Figure 4. Experiment I: Mean activity, as measured by photocell counts, for each of the three groups over the 5 successive test days. 
Table 1

Protocol for Experiment 2: D = Drug group, C = Control group.

\begin{tabular}{lccccccc}
\hline Day & 1 & 2 & 3 & 4 & 5 & 6 & 7 \\
\hline Group D & Saline & Drug & - & Saline & Drug & - & Saline \\
Group C & Saline & Saline & - & Saline & Saline & - & Saline
\end{tabular}

motor activity in the situation, and second, that correlation between the two behavioral components is near zero.

The experiment can be compared with two other studies which have manipulated stimulus complexity as a determinant of exploration. Sales (1968) showed that inspection time of stimuli was related to an inverted-U-shaped function of their complexity, whereas approach towards the stimuli had no systematic relationship with that variable. In the present study, a similar distinction was found for inspective exploration and general locomotor activity.

Denny (1975) has recently found that rats prefer environments of increasing complexity. In addition, the level of locomotor activity also increased as a function of increasing complexity. There are, of course, many differences between the present study and that of Denny. In Denny's experiment, the stimulus objects of exploration were distributed over a wide area, and it would therefore be expected that the level of locomotor activity would be contaminated with inspective exploration of these objects. In addition, the long-term nature of that experiment compared with the present one may have resulted in the measurement of behavior not so much exploratory in nature as directed towards alternative ecological goals, such as safety-seeking.

\section{EXPERIMENT II}

To complete the double dissociation of behaviors, it is desirable to manipulate LA and examine the effects of such a manipulation on a steady baseline of exploration. The animals of Group 1 of Experiment I had reached such a steady baseline of exploralion of their exploranda and, hence, effects of d-amphetamine on LA and EM were observed in these animals in a design similar to that of Robbins and Iversen (1973). We may predict that d-amphetamine will increase activity, as in the Robbins and Iversen experiment, while we would expect it to depress or leave unaffected the EM (Kumar, 1969; Wimer \& Fuller, 1965).

\section{Method}

Subjects. The experimental anımals were the rats that had served as Group 1 in Experiment $I$ and 6 rats run under identical stimulus conditions in a replication of Experiment 1 , to give a total of 12 anımals.

Apparatus. The box and stimuli were those used for Experıment $\mathrm{I}$.
Drug. The drug used was d-amphetamine sulfate supplied by Smith, Kline and French. Dosage was $15 \mathrm{mg} / \mathrm{kg}$, the demonstrated maximum of the dose-response curve for activity in a photocell cage.

The drug was dissolied no $09 \sigma_{0}^{\prime}$ salıne at $15 \mathrm{mg} / \mathrm{ml}$ Salıne alone was used for control injectrons $\mathbf{A l l}$ injections were made intraperitoneally $30 \mathrm{~mm}$ before the onset of the trial

Procedure. The 12 rats were divided into two groups of 6 each, contaning 3 rats from Group 1 of Experiment 1 and 3 of the additional rats. All subjects were run under the same stimulus conditions and in the same general way as Circup 1 of Experiment I

Five daily sessions of 5 min each were run, and the order of drug and placebo injections is given in Table 1.

On Days 2 and 5. Ciroup D (drug) recelved injections of d-amphetamıne, whıle Group ( (control) recesved salıne alone

\section{Results}

All results reported are for the first minute of each session. Results over the full $5 \mathrm{~min}$ were very similar.

Mean scores for exploration of the stimuli are given in Figure 5. These results were analyzed by means of three planned contrasts comparing (a) mean scores of Group D rats on drug days with the mean scores of the same rats over control days, (b) mean scores of Group D rats on drug days with the mean scores of Group C rats on drug days, and (c) mean scores of Group D rats on all control days with the mean scores of Group $C$ rats on all control days. The results of these tests were as follows: (a) $\mathrm{t}=4.02, \mathrm{df}=5, \mathrm{p}<.01 ;$ (b) $\mathrm{t}=3.15$, df $=10, p<.01 ;$ (c) $t=1.16$, df $=10$, n.s. From this result, we may deduce that on drug days Group D explored less than on control days and less than Group C did on drug days. The two groups did not differ on control days.

Mean scores of activity are given in Figure 6. These results were analyzed as above with the following results: (a) $\mathrm{t}=2.98, \mathrm{df}=5, \mathrm{p}<.025$;

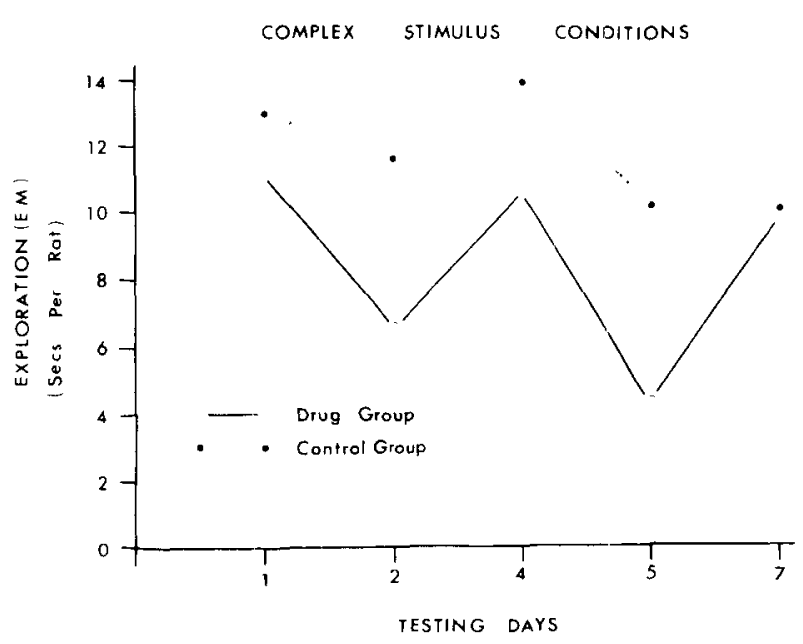

Figure 5. Experiment II: The effects of $1.5 \mathrm{mg} / \mathrm{kg} \mathrm{d}$-amphetamine on mean duration of exploration (E.M.) in seconds. The drug was administered on Days 2 and 5. 


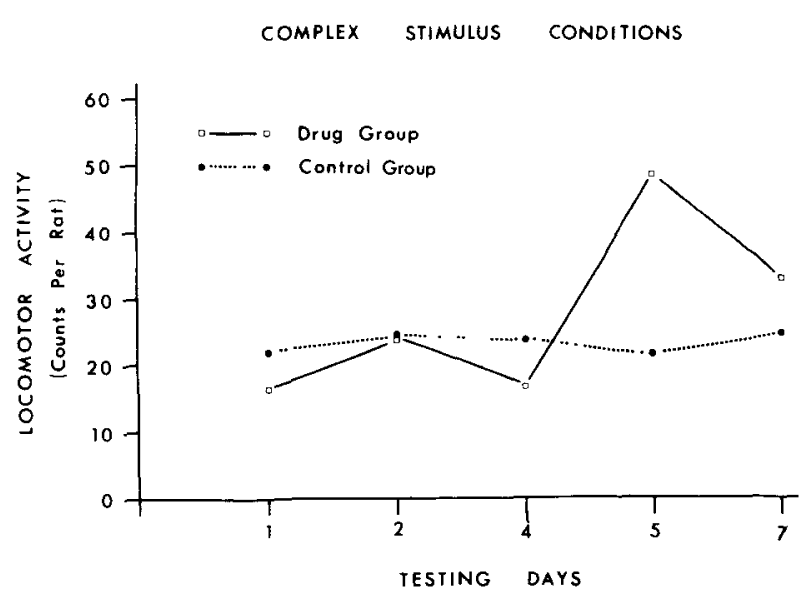

Figure 6. Experiment II: The effects of $1.5 \mathrm{mg} / \mathrm{kg} \mathrm{d}$-amphetamine on activity as measured by photocell counts. The drug was administered on Days 2 and 5.

(b) $\mathrm{t}=2.57$, df $=10, \mathrm{p}<.025 ;$ (c) $\mathrm{t}=0.29$, df $=10$, n.s.

From these results, we may deduce that on drug days Group D were more active than on control days and more active than Group $\mathrm{C}$ on drug or control days. The two groups did not differ on control days.

Intrasubject product-moment correlations of activity and exploration measures were computed on each day both over the first minute and over the full $5 \mathrm{~min}$. In every case, the coefficient was found to be less than 0.20 , and in no case did it approach significance.

\section{Discussion}

The rat under the influence of d-amphetamine were more active and explored less than the rats not under the influence of the drug. These results indicate that, as predicted, amphetamine increased LA. In this case, exploration was reduced by the drug. Again, a clear dissociation of two behaviors was produced and near-zero correlation of the two measures further indicated their distinctness.

In support of these findings, File and Wardill (1975), using a modified hole board, have recently shown that amphetamine reduces the duration of head dips into holes beneath which are novel objects, while simultaneously increasing the level of locomotor activity in mice.

Thus, the double dissociation of behaviors has been satisfactorily demonstrated, and this draws attention to the significance of an adequate examination of locomotor behavior assumed to be exploratory in nature. It has been clearly shown here that the index of LA under observation is quite distinct from a simultaneous measure of exploration. It would be advisable therefore to include such simultaneous measures in all experiments purporting to manipulate either activity or exploration in order to avoid the possibility of confounded effects.

\section{REFERENCES}

BERLYNE. D. E. Novelty and curiosity as determinants of exploratory behaviour. British Journal of Psychology, 1950. 41, 68-80.

Berly NE, D. E. Arousal and satiation of perceptual curiosity in the rat. Journal of Comparative and Physiological Psychology, 1955, 48, 238-246.

Berlyne, D. E. Conflict, arousal and curiosity. New York: McGraw-Hill, 1960.

Bindra, D., \& SPInner, N. Response to different degrees of novelty. Joumal of the Experimental Analysis of Behavior, 1958, 1, 341-350.

Corman, D. C., \& Shafer, J. N. Open field activity and exploratory behaviour. Psychonomic Science, 1968, 13, 55-56.

DENNY. N. S. The rat's long-term preference for complexity in its environment. Animal Learming and Behavior, 1975, 3, 245-249.

File, S. E., \& Wardill, A. G. Validity of head dipping as a measure of exploration in a modified holc board. Psychopharmacologia (Berl.), 1975, 44, 53-59.

Foshee, D. P., Vierck, I. J., Meier, J. N., \& Federsiel, C. Simultaneous measures of general activity and exploratory behaviour. Perceptual and Motor Skills, 1965, 20, 445-451.

KumaR, R. Exploration and latent learning: Differential effects of dexamphetamine on components of exploratory behaviour in rats. Psychopharmacologia (Berl.), 1969, 16, 54-72.

LESTER, D. Effects of fear and anxiety on exploration and curiosity. Journal of General Psychology, 1968, 79, 105-120.

LoRe, R. K. Activity drive hypothesis. Psychologicai Bulletin, 1968, 70. 566-574.

Montgomery, K. C. Relation between fear arising from novel stimulation and exploratory behaviour. Joumal of Comparative and Physiological Psychology, 1955, 48, 254-260.

Robbins. T. W., \& IVERsen, S. D. A dissociation of the effects of d-amphetamine on locomotor activity and exploration in rats. Psychopharmacologia (Berl.), 1973, 28, 155-164.

SALES, S. M. Stimulus complexity as a determinant of approach behavior and inspection time in the hooded rat. Canadian Journal of Psychology, 1968, 22, 11-17.

SChNeIder, J., \& Gross, C. G. Curiosity in the hamster. Journal of Comparative and Physiological Psychology. 1965, 59, 150-152.

Stein berG, H., Rushton, R., \& Tinson, C. Modification of the effects of amphetamine-barbiturate mixtures by past experience of rats. Nature, 1961, 192, 533-535.

Wimer, R. E., \& Fuller, J. L. Effects of d-amphetamine on exploratory behaviour. Canadian Journal of Psychology, $1965,19,94-103$.

WINER, B. J. Statistical principles in experimental design (1st ed.). New York: McGraw-Hill, 1962.

Woons, P. J., \& Davioson, E. H. The behavioural effects of changes in environmental complexity. Canadian Joumal of Psychology, 1964, 18, 23-27.

(Received for publication October 14, 1975; revision accepted January $5,1976$. 